\title{
Tethering of the conus medullaris within the sacrum
}

\author{
D. YASHON ${ }^{1}$ AND R. A. BEATTY \\ From the Department of Neurology and Neurological Surgery, College of Medicine, University of \\ Illinois, Chicago, U.S.A.
}

Included among various forms of craniovertebral congenital defects, known generally as spinal dysraphism or myelodysplasia, is a little described condition produced by the conus medullaris being tethered within the confines of the sacrum, usually by a lipomatous growth. Diagnosis may be difficult and is often not considered by clinicians in spite of characteristic clinical and radiographic appearances. Previous writers on anomalies of the central nervous system have seldom considered this entity separately although treatment differs from that in all other lumbosacral myelodysplasias. Three successive cases are now presented, the relevant embryological and clinical literature is reviewed, and emphasis is placed on positive contrast diagnosis and proper definitive therapy.

\section{CASE REPORTS}

CASE 1 This 6-year-old white boy was born on 18 August 1958 after a full-term uneventful pregnancy. At birth a lipomatous lumbar swelling was noted but disregarded. He developed normally, walked, and rode a tricycle. In August 1963 he began to develop spasticity, particularly of the thigh adductors, and to fall frequently. Over the next six months he gradually became incontinent. Significant in the family history was a paternal grandfather who was reported to have had rachischisis. The patient was admitted to another hospital in August 1964. Examination revealed a lipomatous mass in the lumbosacral area, spasticity, and wasting of the legs, no sensory loss, and urinary incontinence. On 11 August 1964 the superficial lipoma was removed and a laminectomy of L3, L4, and L5 was performed after which a fatty tumour rose into the wound. The dura was not identified and the procedure was terminated. Postoperatively the neurological loss progressed.

Examination in January 1965 revealed an alert, intelligent, normocephalic boy. The upper part of the body was normal but he had bilateral hip flexion contractures and pes valgus. The only voluntary motion remaining in the lower extremities was adduction of the left thigh. Patellar reflexes were hyperactive bilaterally, but ankle reflexes were absent. Abdominal and cremasteric reflexes were absent. Bilateral extensor plantar responses were shown. Perception of pin and touch were diminished

${ }^{1}$ Present address: Department of Neurological Surgery, Cook County Hospital, Chicago, Illinois. up to the knee bilaterally. The perineum was anaesthetic and vibration sense was lost at the ankles. Micturitiog was automatic.

Spinal films demonstrated the surgical laminectom $\frac{D}{p}$ and bifid lumbar and sacral vertebrae (Fig. 1). Am electromyogram showed decreased motor unit activites in the legs. No fibrillation potentials were seen. An intravenous pyelogram was normal. Cisternal positive con $P$ trast myelography showed a distended, low-lying thecat sac extending deeply into the sacrum and curving to the

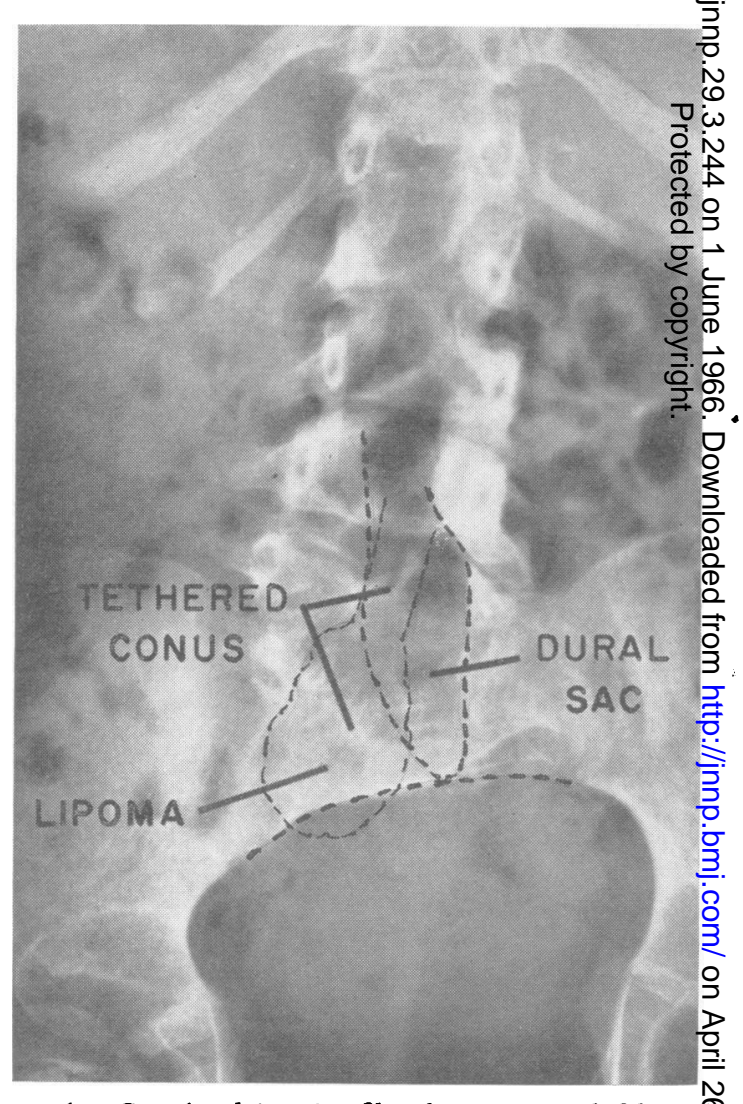

FIG. 1. Case 1: plain spine film showing spina bifida and previous partial laminectomy. Superimposed line drawing 0 demonstrate the position of the lipoma, the attachment of the conus, and the level of the thecal sac. 
right. The spinal cord could not be identified nor any Arnold-Chiari malformation. roof of the sacrum were found to be defective. An incomplete dura was opened and nerve roots were seen to be travelling upwards. The empty enlarged thecal sac curved to the right and the conus medullaris extended into a large sacral lipoma, which was both intra- and extradural, and lying on the left (Fig. 1). This mass was dissected and divided as far caudad as possible allowing the cord to rise and tension to be decreased. No attempt was made to close the dura primarily. The postoperative course was uneventful with no immediate improvement. On examination nine months later there was no improvement over the patient's pre-operative condition.

CASE 2 This 12-year-old girl was born with a sacral mass, said to have been lipomatous, which was removed at the age of 18 months. As development progressed it was apparent that she had no perineal sensation although she crawled and later walked normally. She had stationary urinary and faecal incontinence up to one year

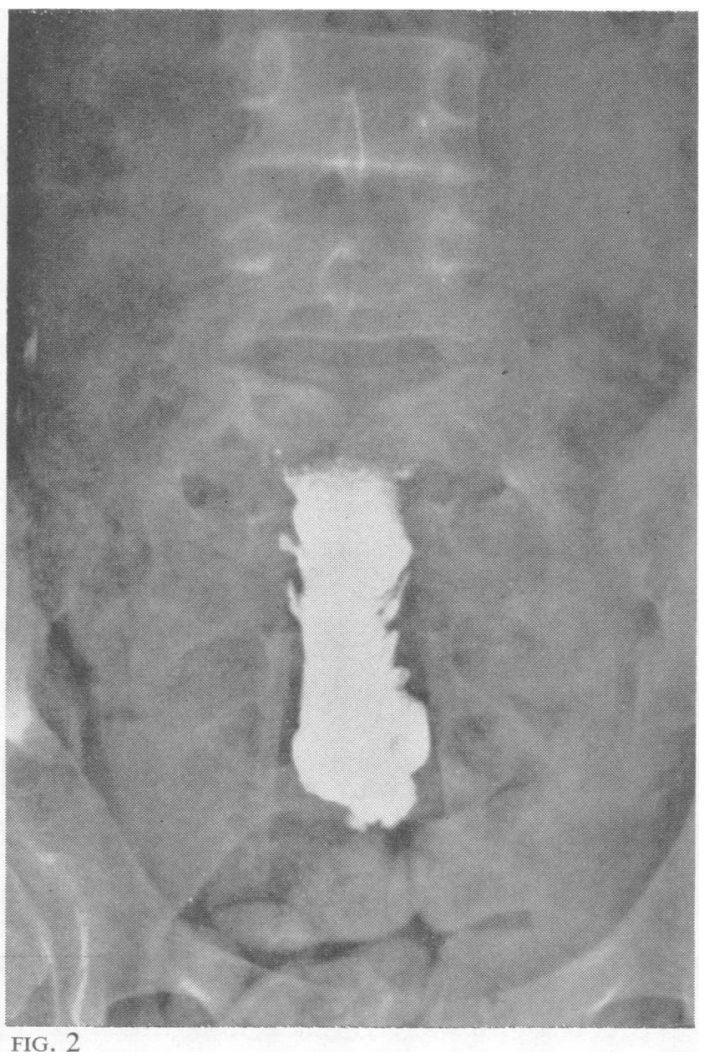

On 2 February 1965 an extensive lumbosacral laminectomy was performed, and most of the laminae and the

before admission when some rectal sphincter control was gained spontaneously. In March 1964 after she had fallen down several stairs low back pain developed. In July 1964 her left leg became weak but improved within 10 days. Twenty-four hours before admission she again fell and developed weakness of the left leg. A maternal aunt had a low back tumour excised which contained hair and teeth but her symptoms were not so severe. Otherwise there was no significant family history.

On examination on 21 October 1964 the patient was unable to move her left leg. There was no atrophy and muscle tone was normal. She had bilateral pes cavus and a right thoracic scoliosis. The perineum and perianal areas were anaesthetic. Abdominal reflexes were intact and extensor plantar responses were present bilaterally. Tendon reflexes were normally active in the legs.

Spinal films showed bifid laminae of L5 and sacral segments. A cystometrogram was consistent with a spastic reflex bladder. Myelography by the lumbar route demonstrated an enlarged, low-lying thecal sac with upward directed nerve root sleeves (Figs. 2, 3).

On examination on 2 December 1964 the findings were unchanged, and laminectomy was performed on 7

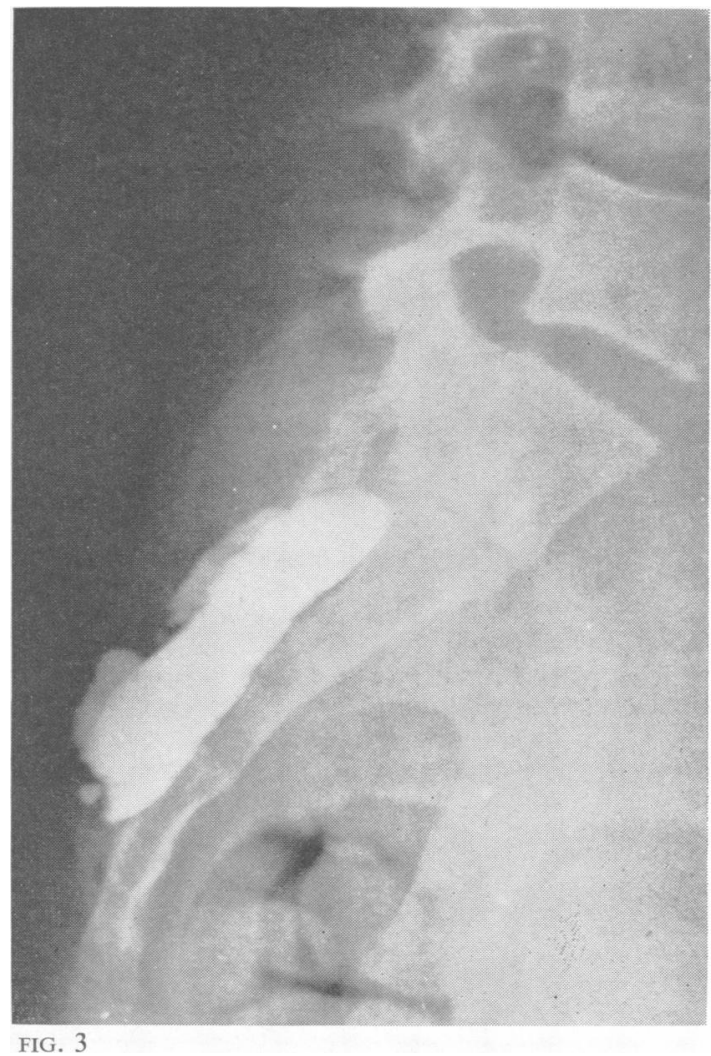

FIG. 2. Case 2: lumbar myelogram showing enlarged low-lying thecal sac and upward directed nerve root sleeves.

FIG. 3. Case 2: lateral view of myelogram. 
December. The sacrum was entirely open. The dura was opened, found to be defective at its caudal end, and merging into a lipomatous growth. The spinal cord and conus medullaris extended into the large sacral lipoma and all sacral roots found their exit cephalad. The lipoma was dissected from its attachment which was at the skin of the lower end of the scar remaining from the previous excision in infancy. Tension on the spinal cord was markedly reduced. Post-operatively movement of the left leg improved but sensation was unchanged. On 2 March 1965 she was able to walk normally, but still had urinary incontinence and sacral anaesthesia. Faecal incontinence had subjectively improved even further. The extensor plantar response was absent on the left and present on the right. Tendon reflexes were hypoactive in the knees but normally active at the ankles. In May 1965 the patient was readmitted with weakness of both legs and bilateral extensor plantar responses. Over a three-week period of bed rest the weakness partially disappeared. In the ensuing six months the patient remained ambulatory on crutches. A suprapubic cystostomy has been required.

CASE 3 This 14-year-old white boy had a two-year history of unexpected episodes of spontaneous micturition, which had been increasing in frequency. For many years the patient had urinary urgency and was noted to stumble often. At the age of 6 months a draining sinus consistent with a pilonidal cyst of the midline coccygeal area was first noted by physicians. The patient had a similar draining dermal sinus in the midline at L5 since birth. Lumbosacral radiographs revealed spina bifida occulta. At 17 months the patient had $E$. coli meningitis which was treated successfully. On 2 March 1952, at 18 months, a lumbar laminectomy was performed, the lumbar sinus tract resected, followed into its communication with the dura, and the dura closed. The pilonidal cyst was not removed. Subsequent development was normal including all sensory and motor function.

On examination a lumbar scar was visible and the pilonidal cyst had healed, its only trace being a coccygeal skin dimple. Rectal tone was poor and many scars were visible on the legs. Positive neurological findings were restricted to the lower extremities where tone was increased. Muscle strength was good, however, and the patient had a normal gait. Bilateral unsustained ankle clonus was present and deep tendon reflexes in the legs were hyperactive. Extensor toe signs were absent. Abdominal and cremasteric reflexes were retained, and all sensory modalities were intact, including those in the perineal area.

A cystometrogram was consistent with a spastic bladder. An intravenous pyelogram was within normal limits. An electromyogram showed fibrillation potentials scattered throughout the lower extremities.

On lumbosacral radiographs the extensive spina bifida occulta was visible. On 4 September 1965 a cisternal myelogram revealed a large thecal sac extending deeply into the sacro-coccygeal area. Although nerve roots could not be seen the negative shadow of the spinal cord was visualized in the sacral area so that the diagnosis of a tethered conus was suspected. A laminectomy of lumbar, sacral, and coccygeal areas was performed. The conu medullaris was attached, within a lipoma, to the coccyge skin dimple by means of fibrous tissue strands. Nerfe roots found an exit upwards and dense adhesions we present. Although the lipoma was freed and the cord was seen to travel cephalad after tension was relieved, radical operation could not be performed safely for fear of damage to vital nerve roots. Postoperatively the patiedid well and experienced no neurological loss as a resu费 of surgery. After a seven-month follow up, the sam symptoms and signs were present as pre-operatively; but they had not progressed.

\section{DISCUSSION}

The tethered conus medullaris is part of the large group of midline embryological defects collective known as myelodysplasia or spinal dysraphisifn (Lichtenstein, 1940). The many variants comprising the larger groups have been discussed by Fisher: Uihlein, and Keith (1952), and Cohn and Hambey (1953). These defects are thought to occur in ear gestation by a process of abnormal or arreste maturation and involve mesodermal structures. skin, or neural elements in combination or alone As a result of such embryonal dysplasia variọuis clinical conditions, including defects of the verte arch, dural and neural tube fusion anomaties cutaneous cysts and sinuses, ectopic gangtia, and other defects may result (Lichtenstein, 1940 The embryological aspects have been extensigel reviewed by Saunders (1943). Defects under generat discussion here are restricted to those which have prevented normal cephalad migration of the conus. medullaris, namely, sacral tumours (dermoids an lipomata), fibrous traction bands, and tight fils terminale (Jones and Love, 1956) because ō clinical examination they may be indistinguishable These can occur as occult neural defects but ars usually associated with a lumbosacral spina bifid高 (Lichtenstein, 1942).

Streeter (1919) has shown that in normal foetat development before the 11-15 $\mathrm{mm}$. stage, the cor $\$$ extends to the lower end of the sacrum, and it is at this stage that the conus medullaris becomes fixe within the sacrum. Normally the dorsal nerve roots become attached to the cord before the conus. medullaris ascends and thereafter are useful fo: marking various stages of ascent. At this time the nerve roots are horizontal but after the $30 \mathrm{~mm}$. stage the vertebral column lengthens caudad more rapidly than the spinal cord and the roots then take a downe ward course (Streeter, 1919). During this time the filum terminale is formed by atrophy of distat segments of the cord leaving a residual ependymail strand. The formation of the filum terminale may also account for further ascent of the conus. The 


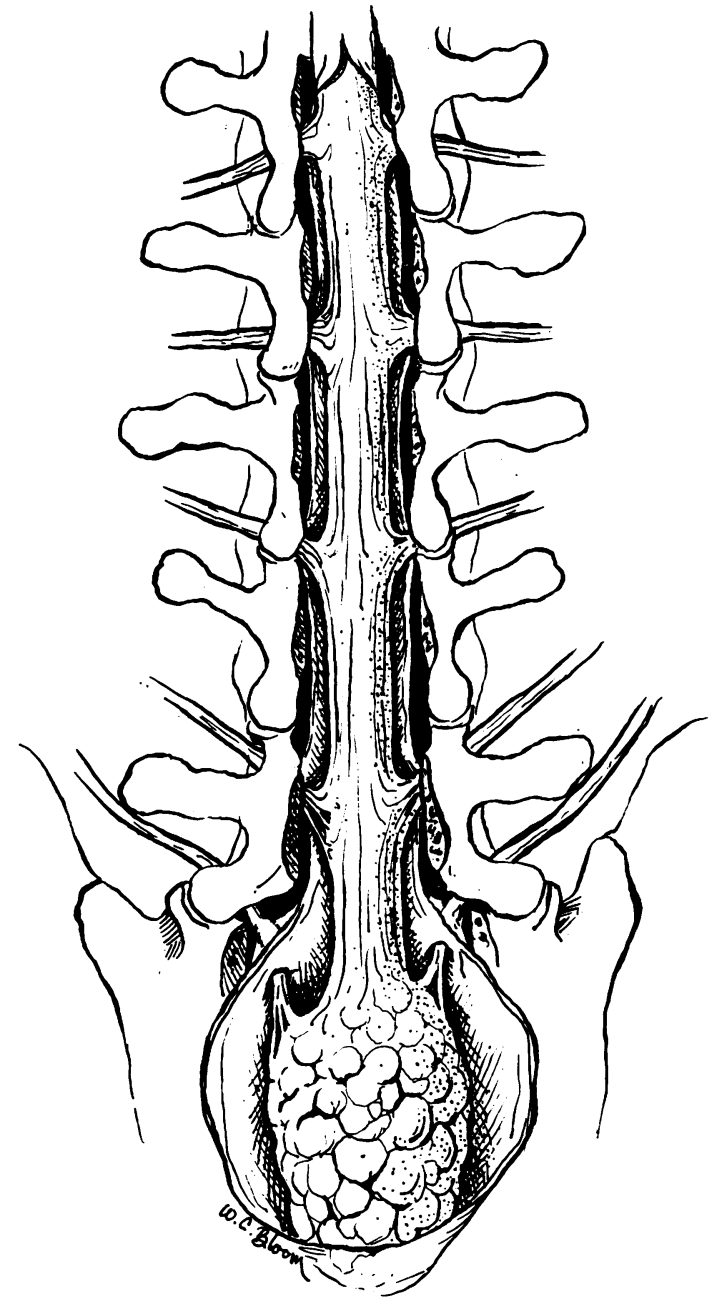

FIG. 4. Schematic drawing of usual pathology encountered. Note the conus tethered by fatty tumour, upward directed nerve roots, and increased distance between the more caudad nerve segments.

remainder of ascent takes place during the first 25 weeks of gestation after which the conus is at the third lumbar level. Before the adult level is reached the conus must normally ascend two further segments (Reimann and Anson, 1944).

Several theoretical anatomical mechanisms have been proposed to explain the low-lying conus. The first is that the spinal cord grows at a rate commensurate with the vertebral column at all stages of development. This proposition seems unlikely when the cephalad direction of the sacral roots is considered in the presence of normal downward directed lumbar and thoracic roots (Lichtenstein, 1942; Reimann and Anson, 1944). Further, Reimann and Anson showed that in cases in which the conus is trapped the distance between nerve segments in the lumbosacral area is greater than normal which suggests a stretching process rather than active growth. Gardner (1964) has explained the spinal dysraphic syndromes by postulating that inadequate permeability of the rhombic roof causes hydromyelia, distension of the central neural canal, and finally fusion of germ layers either cephalad or caudad as in the cases under discussion. It has been postulated that lumbar diastomyelia and myelomeningocele occur in this manner. If this theory can be applied to sacral tethering one must postulate that germ layers became fused in the sacral rather than in the lumbar area. Traction due to primary lumbosacral fusion has been invoked as a cause of the low-lying conus (Lichtenstein, 1940). Evidence for this is seen at the operating table when tethering is relieved and the cord rises immediately. Not one of our patients had a detectable Arnold-Chiari malformation which conceivably might result from such traction from below.

Clinical symptoms produced by the stretched cord from whatever cause have already been described (Brickner, 1918; Ingraham and Lowrey, 1943; Garceau, 1953; Jones and Love, 1956; James and Lassman, 1960; Love, Daly, and Harris, 1961). Such varied symptoms and signs as enuresis, foot deformities, trophic pedal ulcers, scoliosis, and progressive neurological deficits in the lower extremities occur. Typically, the symptoms appear or become worse during two periods of life. First, when the child assumes the erect posture and second, during the period of rapid growth of early adolescence (Jones and Love, 1956). The common presentation is generally an unexplained progressive spasticity during these two periods of life superimposed on a background of urinary difficulties. Differentiation from certain other myelodysplasias, such as the Arnold-Chiari malformation (Peach, $1965 a$ and b), may be difficult. In each of our cases a lumbosacral scar from previous surgery was present. The presence of a dermal defect is not a prerequisite of the condition but in almost all cord traction syndromes a spina bifida is present.

To explain the prominent signs of an upper motor neurone lesion Katzenstein (1901) formulated the theory that caudal traction on nervous tissue may result in proximal degeneration. However, Barry, Patten, and Stewart (1957), by measuring distances between nerve segments, showed that those distances immediately above the point of tethering are greater than normal, and stated that this effect of traction from below is dissipated within five nerve segments. Distant effects of stretching may, however, cause more proximal microscopic or physio- 
logical changes. The stretching may affect the large diameter nerve fibres of the corticospinal tracts by the same mechanism by which Kahn (1947) postulated that the spinal cord is fixed by the dentate ligaments in cervical spondylosis. These larger fibres are more vulnerable to metabolic and physical disturbances than smaller fibres (Kahn, 1947). In some cases there may be concomitant distant neuroanatomical defects in the posterior fossa or along the thoracic cord which might explain the spasticity which is often seen (Lichtenstein, 1942; McKenzie and DeWar, 1949; Shorey, 1955). In our cases myelographic and clinical evidence of other neuroanatamical defects was absent.

Diagnosis of a conus medullaris tethered within the sacrum may be established by positive contrast myelography. In any child presenting with progressive neurological deficiencies in the lower extremities against a background of urinary difficulties the diagnosis of a conus traction syndrome must be suspected. Even in the presence of a normal vertebral column a low-lying conus cannot be excluded. A lower than normal dilated thecal sac is suggestive. Swedberg (1963) has advocated the use of negative contrast gas myelography in cases of myelomeningocele. He was able to identify the level of the conus and to show abnormal fixation of the cord to the vertebral column. He was, however, unable to demonstrate the direction of nerve roots. Nerve roots which are seen, on contrast study, to find an exit upwards are pathognomonic of fixing the spinal cord within the sacrum. Gryspeerdt (1963) presented the myelographic findings in James and Lassman's (1962) cases of occult spinal dysraphism. Fifty-one cases had positive contrast myelographic studies. The value of identifying the level of the conus medullaris in the supine position or indirectly determining the level by seeing a low-lying anterior spinal artery in the prone position was stressed. We have been unable to define the level of the conus by the anterior spinal artery at this level. Taveras and Wood (1964), on the other hand, regard the prone position as superior in defining the level of the conus medullaris. Gryspeerdt (1963) was able to demonstrate wide fila, fibrous bands, and ossified and unossified septa. The direction of nerve roots was not visualized. Bleasel (1961) has delineated the cauda equina and conus medullaris by utilizing an emulsion of Myodil and spinal fluid. This technique renders the material being examined more radiolucent and so provides a better outline of the spinal cord and nerve roots. If the shadow of the spinal cord can be seen in the lumbosacral area a tethered conus medullaris is suggested.

Walker (1944) pointed out that often in cases of myelodysplasia the bony vertebral canal is seen to be widened on plain radiographs. He presente\& one case, similar to ours, with a sacral lipoma an upward directed nerve roots which was treated bF unroofing the sacrum. In the case of Alexandere Garvey, and Boyce (1954) the nerve roots were see to find an exit upwards at the time of surgery but in this instance the conus medullaris was bound dowe by scar tissue, not lipoma, at L5-S1. Continence of urine was restored after the third sacral roots werg. crushed bilaterally. Bassett (1950) described lipomas of the cauda equina in nine patients, and some of them were in an abnormally low position. Campbeif (1962) discusses good post-operative results if several cases. In our cases beneficent effects of surgical treatment are not proved. There are othe available reports in which the conus medullaris was found to be tethered, but generally by tight fila, scam tissue, or neoplasm (Meredith, 1944; Jacksorb Thompson, Hooks, and Hoffman, 1956; Jones and Love, 1956).

Gryspeerdt (1963) noted that of 32 consecutive cases of occult spinal dysraphism there were $n \overline{8}$ cases of the Arnold-Chiari malformation. Hie therefore regarded cisternal puncture as safe्ध.ं Russell and Donald (1935) agreed that in spointo bifida occulta the hind brain is usually norriat However, in 10 consecutive cases of meningocele they showed the presence of the type II Arnotde Chiari malformation and cautioned against cisternal puncture. Daniel and Strich (1958) discussedô 26 cases of the Arnold-Chiari malformation allsof which had a meningomyelocele. One fat occurred after cisternal puncture in a patient witP meningomyelocele. Campbell (1962) has dis continued pre-operative diagnostic studies because he feels insufficient information is gained to justif the risk of trauma to neural elements, but valuabs information was gleaned from the pre-operatis positive contrast studies in our cases and recommend such studies. From this evidence $\frac{P}{8}$. would appear that a contrast study is desirable but should be performed cautiously in any child suss pected of having a cord traction syndrome (Lis 1941; Cameron, 1957). If an Arnold-Chiari mats formation is present, cisternal puncture for instillation of contrast material carries risk. On the other. hand if symptoms are due to a low-lying conis medullaris, lumbar puncture is theoretically hazarct. ous.

The surgical approach varies with the severity of the lesion. In cases of tight fila terminale the conts - seldom extends into the sacrum and the nerve roots travel downward. Here a simple lumb laminectomy and division of the tight filum sufficis (Ingraham and Lowry, 1943). In cases of conys medullaris caught below the sacrum the deformity $\frac{15}{0}$ 
more severe and the junction between conus and lipoma is unclear. The conus extends deeply into the sacrum and nerve roots take a cephalad direction.

Generally the conus is bound down by a fibrofatty tumour. In these cases the laminectomy should begin in a relatively normal lumbar area and proceed caudad. If the laminectomy begins in the sacrococcygeal area there is a greater risk of neural damage. The dura must be opened. In a series of 474 cases of spina bifida Ingraham (1943) showed that 45 cases were associated with lipomata. Hauge (1963) described such a case in which the sacral roof was removed and the conus freed from a fatty tumour. Four days after operation the patient controlled micturition for the first time in his 16 years of life. On the other hand Garceau (1953) described a patient who had three laminectomies before the sacrum was unroofed and a short thick filum was divided. In our cases there was initially a failure to recognize the nature of the lesion. Had a more aggressive approach been taken earlier, much neurological function might have been preserved. Beneficial effects of adequate surgery have not been proved in our series although progression of the neurological defects has probably been halted. This is in contradistinction to some of Campbell's (1962) cases and other cases previously cited. The problem of management of the accompanying urinary tract involvement depends on the success or failure of neurosurgical therapy and has been extensively discussed (Mertz and Smith, 1930; Gross, Holcomb, and Swan, 1953; Morales, Deaver, and Hotchkiss, 1956).

These cases are examples of tethering occurring during the first month of gestation usually by a lipomatous growth and therefore differ from cases of tight fila terminale or other traction bands. This distinction can be made pre-operatively by myelography or at the time of laminectomy by noting the direction of nerve roots and the level of the conus after the dura is opened. Nothing less than unroofing of the sacrum and dissection from below to release the tethered conus from its point of attachment can be considered adequate. In other forms of tethered conus, such as a tight filum terminale or certain fibrous traction bands, an ordinary lumbar laminectomy may be considered adequate.

\section{SUMMARY}

A congenital anomaly, tethering of the conus medullaris by a lipomatous tumour within the sacrum, can be diagnosed pre-operatively by myelographic identification of the length of the spinal cord, the caudal extent of the thecal sac, and the direction which the nerve roots take in the caudally displaced thecal sac. Upwards directed nerve roots are diag- nostic and indicate that the dissection should be carried into the sacrum below the lipoma for release of traction. In this report the beneficent effect of adequate surgery in three cases is questionable.

\section{REFERENCES}

Alexander, E. Jr., Garvey, F. K., and Boyce, W. (1954). Congenital lumbosacral myelomeningocele with incontinence. J. Neurosurg., 11, 183-192.

Barry, A., Patten, B. M., and Stewart, B. H. (1957). Possible factors in the development of the Arnold-Chiari malformation. Ibid., 14, 285-301.

Bassett, R. C. (1950). The neurological deficit associated with lipomas of the cauda equina. Ann. Surg., 131, 109-116.

Bleasel, K. (1961). Nerve root radiography. Brit. J. Radiol., 34, 596-601.

Brickner, W. M. (1918). Spina bifida occulta. Amer. J. med. Sci., 155, 473-502.

Cameron, A. H. (1957). The Arnold-Chiari and other neuro-anatomical malformations associated with spina bifida. J. Path. Bact., 73, 195-211.

Campbell, J. B. (1962). Neurosurgical treatment of bladder and bowel dysfunction resulting from anomalous development of the sacral neural axis. Clin. Neurosurg., 8, 133-156.

Cohn, G. A., and Hamby, W. B. (1953). The surgery of cranium bifidum and spina bifida. $J$. Neurosurg., 10, 297-300.

Daniel, P. M., and Strich, S. J. (1958). Some observations on the congenital deformity of the central nervous system known as the Arnold-Chiari malformation. J. Neuropath. exp. Neurol., 17, 255-266.

Fisher, R. G., Uihlein, A., and Keith, H. M. (1952). Spina bifida and cranium bifidum: study of 530 cases. Proc. Mayo Clin., 27, 33-38.

Garceau, G. J. (1953). The filum terminale syndrome. J. Bone Jt Surg., 35A, 711-716.

Gardner, W. J. (1964). Diastematomyelia and the Klippel-Feil syndrome; relationship to hydrocephalus, syringomyelia, meningocele, meningomyelocele, and iniencephalus. Cleveland Clin. Quart., 31, 19-44.

Gross, R. E., Holcomb, G. W. Jr., and Swan, H. (1953). Treatment of neurogenic urinary and fecal incontinence in children. Arch. Surg., 66, 143-154.

Gryspeerdt, G. L. (1963). Myelographic assessment of occult forms of spinal dysraphism. Acta radiol. Diagn. (Stockh.), n.s. 1, 702-717.

Hauge, T. (1963). Myelography in a case of the occult form of spinal dysraphism. Ibid., 718-720.

Ingraham, F. D., and Lowrey, J. J. (1943). Spina bifida and cranium bifidum, III. Occult spinal disorders. New Engl. J. Med., 228, 745-750.

- (1943). Spina Bifida and Cranium Bifidum, p. 4. Harvard University Press, Cambridge, Mass.

Jackson, I. J., Thompson, I. M., Hooks, C. A., and Hoffmann, G. T. (1956). Urinary incontinence in myelomeningoceles due to a tethered spinal cord and its surgical treatment. Surg. Gynec. Obstet., 103, 618-624.

James, C. C. M., and Lassman, L. P. (1958). Diastematomyelia. Arch. Dis. Childh., 33, 536-539.

,$--(1960)$. Spinal dysraphism: an orthopaedic syndrome in childhood accompanying occult forms. Ibid., 35, 315-327.

- - (1962). Spinal dysraphism; the diagnosis and treatment of progressive lesions in spina bifida occulta. J. Bone Jt Surg., 44B, 828-840.

Jones, P. H., and Love, J. G. (1956). Tight filum terminale. Arch. Surg., 73, 556-566.

Kahn, E. A. (1947). The rôle of the dentate ligaments in spinal cord compression and the syndrome of lateral sclerosis. J. Neurosurg., 4, 191-199.

Katzenstein, M. (1901). Beitrag zur Pathologie und Therapie der Spina bifida occulta. Langenbecks Arch. klin. Chir., 64, 607-629.

Lichtenstein, B. W. (1940). Spinal dysraphism. Spina bifida and myelodysplasia. Arch. Neurol. Psychiat. (Chic.), 44, 792-810.

(1942). Distant neuroanatomic complications of spina bifida. Ibid., 47, 195-214.

List, C. F. (1941). Neurologic syndromes accompanying developmental anomalies of occipital bone, atlas and axis. Ibid., 45, 577-616. 
Love, J. G., Daly, D. D., and Harris, L. E. (1961). Tight filum terminale. Report of condition in three siblings. J. Amer. med. Ass., 176, 31-33.

McKenzie, K. G., and Dewar, F. P. (1949). Scoliosis with paraplegia. J. Bone Jt Surg., 31B, 162-174.

Meredith, J. M. (1944). Unusual congenital anomalies of the lumbosacral spine (spina bifida) with a report of three cases. J. nerv. ment. Dis., 99, 115-133.

Mertz, H. O., and Smith, L. A. (1930). Posterior spinal fusion defects and nerve dysfunction of the urinary tract. J. Urol. (Baltimore), 24, 41-82.

Morales, P. A., Deaver, G. G., and Hotchkiss, R. S. (1956). Urological complications of spina bifida in children. Ibid., 75, 537-550.

Peach, B. (1965a). Arnold-Chiari malformation. Arch. Neurol. (Chic.), 12, 613-621.

(1965b). The Arnold-Chiari malformation. Ibid., 12, 527-535.

Reimann, A. F., and Anson, B. J. (1944). Vertebral level of termination of the spinal cord with report of a case of sacral cord. Anat Rec., 88, 127-138.

Russell, D. S., and Donald, C. (1935). The mechanism of internalo hydrocephalus in spina bifida. Brain, 58, 203-215.

Saunders, R. L. deC. H. (1943). Combined anterior and posterioro spina bifida in a living neonatal human female. Anat. Rec.?

87, 255-278.
Shorey, W. D. (1955). Diastematomyelia associated with dorsal kyphosis producing paraplegia. J. Neurosurg., 12, 300-305.

Streeter, G. L. (1919). Factors involved in the formation of the filums terminale. Amer. J. Anat., 25, 1-11.

Swedberg, M. (1963). Meningo- and myelomeningocele studied by gas myelography. Acta radiol, Diagn. (Stockh), n.s.1, 796-805

Taveras, J. M., and Wood, E. H. (1964). Diagnostic Neuroradiology. p. 1.856. Williams and Wilkins, Baltimore.

Walker, A. E., (1944). Dilatation of the vertebral canal associated with congenital anomalies of the spinal cord. Amer. J. Roentgenol. 52, 571-582. 